Molekulare Infektionsbiologie

\title{
Einzelzell-RNA-Sequenzierung beleuchtet den Infektionsprozess
}

Antoine-Emmanuel Saliba ${ }^{1}$, Alexander J. Westermann ${ }^{2}$, Jörg Voge $1^{1,2}$

${ }^{1}$ Helmholtz-Institut für RNA-basierte Infektionsforschung (HIRI), Würzburg

${ }^{2}$ Institut für Molekulare Infektionsbiologie (IMIB), Universität Würzburg 
Single-cell RNA-seq has revolutionized our understanding of cellular heterogeneity in a wide spectrum of biological processes. Pioneering studies suggest complex mechanisms and division of labor employed by the bacterial pathogen Salmonella to subvert host cell functions during infection. Here we describe some of our findings from single-cell RNA-seq studies that have revealed and characterized heterogeneity between individual cells infected with this intracellular pathogen, and outline future challenges in this burgeoning field.

Trotz erhöhter Hygienestandards und verbesserter Behandlung sind bakterielle Infektionskrankheiten immer noch eine der Haupttodesursachen weltweit. Nach der Infektion können sich bakterielle Erreger in ökologischen Nischen innerhalb des Wirts vervielfältigen und dabei mit unterschiedlichen Wirtszelltypen wechselwirken. Neue Studien zeigen, dass sich dabei unterschiedliche Subpopulationen eines Erregers bilden können [1] (Abb. 1). Eine solche Subpopulation bakterieller Erreger, die sich durch langsames Wachstum sowie Widerstandsfähigkeit gegenüber Antibiotikabehandlung auszeichnet, sind die „Persister“ [2]. Persister schlummern oft über Jahre hinweg unbemerkt in ihrem Wirt, um dann plötzlich schwere Symptome hervorzurufen. Unklar ist, was die Bakterien dazu bewegt, sich innerhalb ihres Wirts unterschiedlich zu verhalten. Erste Ergebnisse sprechen dafür, dass äußere Einflüsse diese Entscheidung teilweise bestimmen: So unterscheidet sich beispielsweise die Stärke der vom infizierten Wirt eingeleiteten, akuten Immunabwehrmechanismen oft zwischen einzelnen Infektionsherden und trägt somit zur Heterogenität der Infektionsprozesse bei [3].

Bisherige Studien von Infektionsprozessen betrachteten meist nur die Gesamtheit von infizierten Zellen. Das Verhalten einzelner Zellen während der Infektion wurde aus dem Durchschnittsverhalten der Zellpopulation abgeleitet. Auf diese Weise wird jedoch die Verschiedenartigkeit einzelner Zellen ausgeblendet. Um diese Heterogenität - und insbesondere ihre Bedeutung für den Ausgang der Infektion - zu erforschen, bedarf es eines erhöhten Auflösungsvermögens der experimentellen Ansätze, wie es Einzelzell-Analysen ermöglichen. Eine dieser Methoden, die Einzelzell-RNA-Sequenzierung oder auch Single-cell RNA-seq hat unser Verständnis bakterieller Infektionen innerhalb kürzester Zeit revolutioniert.

\section{Das Prinzip von Single-cell RNA-seq}

Die Methode der RNA-Sequenzierung beruht darauf, RNA-Transkripte in einer biologischen Probe quantitativ und qualitativ zu erfassen. Dazu werden zelluläre RNA-Moleküle in komplementäre DNAMoleküle (cDNA) umgeschrieben, anschließend mittels PCR (Polymerase-Kettenreaktion) vervielfältigt und schließlich sequenziert. Während dies ursprünglich nur für Probengemische aus oftmals mehreren Millionen Zellen durchgeführt werden konnte, ist die Sensitivität der Technologie mittlerweile so hoch, dass die RNA-Zusammensetzung einzelner Zellen studiert werden kann [4] (Abb. 2). Neuerdings 
können alle Reaktionen sogar nebeneinander, innerhalb eines Nanoliter-Tröpfchens, durchgeführt werden: die Droplet-Sequenzierung (kurz Drop-Seq) (Abb. 2). Dank Drop-Seq erhöht sich der Durchsatz einzeln sequenzierter Zellen dramatisch: Es können mehrere Tausend Zellen innerhalb weniger Stunden studiert werden, zu einem Bruchteil der bisherigen Kosten.

Anschließend bedarf es genauer bioinformatorischer Analysen, um biologische Unterschiede von technischem Rauschen zu trennen. Diese Informationen ergeben dann für jede Einzelzelle eine eigene Transkriptom-Signatur. Dadurch wird es erstmals möglich, Eigenschaften einer Zelle, wie etwa ihre physiologische Beschaffenheit oder den Zelltyp, anstatt aus dem äußeren Erscheinungsbild aus dem RNA-Expressionsprofil abzuleiten. Parallel für mehrere Einzelzellen lassen sich so am Computer unterschiedliche Populationen sich ähnlich verhaltender Zellen rekonstruieren.

Bereits in den wenigen Jahren seit ihrer Einführung lieferte die Einzelzell-RNA-Sequenzierung spektakuläre Ergebnisse: So konnten beispielsweise im Körper vorhandene seltene Zelltypen erstmals auf molekularer Ebene erforscht werden; auch wurden etliche neue Zelltypen entdeckt. Daneben wird Single-cell RNA-seq zunehmend eingesetzt, um das Wechselspiel eines bakteriellen Keims mit seiner Wirtszelle zu untersuchen.

\section{Erforschung infizierter Makrophagen}

Salmonellen gehören zu den am besten charakterisierten Modellorganismen der Mikrobiologie. Sie verursachen Krankheiten wie Magen-Darm-Entzündungen. Dabei sind ausgerechnet spezialisierte Immunzellen des Wirts, die normalerweise bakterielle Eindringlinge abtöten, eine von Salmonellen bevorzugte Nische [2]. Die Salmonellen infizieren diese Makrophagen und manipulieren sie so, dass sie die aufgenommenen Bakterien nicht länger aktiv bekämpfen, sondern ihnen als Schutznische innerhalb des Wirtskörpers dienen. In ihrem "Makrophagen-Container" zeigen Salmonellen unterschiedliche Verhaltensmuster: Manche Bakterien vervielfältigen sich, während sich andere ruhig verhalten und einen Persister-ähnlichen Zustand annehmen (Abb. 1 und 3). Daneben unterscheiden sich auch einzelne Makrophagen voneinander: Insbesondere können sie sich zu grundlegend unterschiedlichen Zellpopulationen entwickeln, die entgegengesetzte Verhaltensmuster an den Tag legen; man spricht hier von Makrophagen-Polarisierung.

Die Anwendung von Single-cell RNA-seq auf infizierte Makrophagen, die jeweils genau eine Salmonelle enthielten, zeigte kürzlich die enormen Unterschiede in der ausgelösten Wirtsantwort auf [5]: Interessanterweise konnte die Grundlage für die verschiedenen Reaktionen der Wirtszellen auf eine den Salmonellen innewohnende Variabilität in der Expression ihrer Virulenzfaktoren zurückgeführt werden (Abb. 3A). Wir untersuchten kürzlich einzelne Makrophagen, die jeweils eine unterschiedliche Anzahl an Salmonellen enthielten (Abb. 4) [6]. Ein für solche Zwecke entwickelter Fluoreszenz-Reporter ermöglicht es uns, das Wachstumsverhalten der Salmonellen innerhalb ihrer 
Wirtszelle nachzuverfolgen. Wir isolierten Makrophagen, die entweder durch sich aktiv vermehrende oder aber nicht-replizierende Salmonellen besiedelt waren, und untersuchten diese Wirtszellen mit Single-cell RNA-seq. Die Ergebnisse zeigen, dass infizierte Makrophagen ihre Polarisierung an das jeweilige Wachstumsverhalten der sie infizierenden Salmonellen knüpfen: Nicht-replizierende Bakterien finden sich in Makrophagen, die pro-inflammatorische Eigenschaften aufweisen und nichtinfizierten, rein extrazellulär stimulierten Nachbarzellen ähneln. Dagegen erinnert die RNA-Signatur der Zellen mit sich vermehrenden Salmonellen an die anti-inflammatorischer Makrophagen (Abb. 3B, Abb. 4). Diese Beobachtungen können so interpretiert werden, dass intrazelluläre Bakterien dazu in der Lage sind, ihre Wirtszell-Umgebung aktiv mitzugestalten. Insbesondere scheint es, als ob sich nichtreplizierende Salmonellen ihrer Erkennung durch den Wirt entziehen. Diese Bakterien scheinen also unter dem Radar der infizierten Makrophagen hindurch zu fliegen.

\section{Was bringt die Zukunft?}

Obwohl als Technologie noch recht jung, hat die Einzelzell-RNA-Sequenzierung bereits enorm zu unserem Verständnis der Heterogenität biologischer Prozesse beigetragen. Zu erwartende technologische Fortschritte, wie etwa der Transfer der Methode von Zellkulturmodellen zu in-vivoModellen oder höher auflösende bioinformatorische Analysen werden solche Einzelzell-Analysen weiter voranbringen. Trotz der hier beschriebenen Entdeckungen steckt die Verknüpfung von Singlecell RNA-seq und Infektionsforschung aber noch in den Kinderschuhen. So ist etwa die RNASequenzierung einzelner Bakterienzellen aktuell noch nicht möglich, um damit wie beim Dual RNA-seq [7] gemeinsam die Zustände sowohl des Erregers als auch des Wirts zu erfassen, nur eben auf der Ebene von einzelnen infizierten Zellen. Darüber hinaus ist es von großer Bedeutung, zukünftig Einzelzell-Analysen durchzuführen, ohne dabei Informationen über die Gewebestruktur einzubüßen, um letztlich Genexpression während einer Infektion mit einhergehenden Gewebeveränderungen in Verbindung setzen zu können. Die übergeordnete Herausforderung ist es zu verstehen, wie einzelne Ereignisse während einer Infektion zusammenwirken und letztlich gemeinsam zum Krankheitsverlauf beitragen.

\section{Bildunterschriften}

Abbildung 1 - Heterogenität während einer Infektion. A, Innerhalb von Makrophagen zeigen Salmonellen unterschiedliches Wachstumsverhalten: Langsam oder nicht-wachsende Bakterien sind rot, sich vermehrende Bakterien grün eingefärbt (C Sophie Helaine). B, Gewebefärbung einer Salmonellen-infizierten Milz einer Maus [3]. Salmonellen (gelbe Pfeile) finden sich in verschiedenen 
Nischen, nämlich entweder einer Neutrophil-angereicherten Umgebung (rosa) oder einer Makrophagen-Zone (türkis).

Abbildung 2-Ablauf der Einzelzell-RNA-Sequenzierung. Ein Zellgemisch oder eine Gewebeprobe wird zunächst vereinzelt (A). Einzelne Zellen werden mittels einer der drei genannten Methoden isoliert und lysiert (B). Die freigesetzte RNA wird durch die Reverse Transkriptase und einen Primer, der an ihr polyadenyliertes 3'-Ende bindet, in cDNA umgeschrieben und anschließend sequenziert (C). Über einen datengesteuerten Ansatz, der die jeweiligen RNA-Signaturen zugrunde legt, können danach einzelne Zellen am Computer größeren Populationen zugewiesen werden (D).

\title{
Box zu Abbildung 2:
}

Durchflusszytometrie: Messverfahren zur Analyse und Sortierung von Zellen in Suspension basierend auf Laser-induzierter Fluoreszenzemmission.

Droplet-Sequenzierung: Mikrofluidik-Technologie, bei der Einzelzellen in nur wenige Nanoliter umfassende Tröpfchen (Droplets) eingeschlossen werden. Diese Methode ermöglicht die individuelle Analyse von Einzelzell-Transkriptomen.

Fluidigm C1: Spezielle Mikrofluidik-Plattform zur automatisierten Anordnung einzelner Zellen in Vertiefungen mit einem Durchmesser von wenigen Mikrometern unter Miteinbeziehung eines fluidischen Netzwerks zur Einzelzell-Transkriptomanalyse.

\begin{abstract}
Abbildung 3 - Unterschiede in der Salmonellen-Infektion von Makrophagen. A, Makrophagen mit jeweils einer intrazellulären Salmonelle wurden mittels Single-cell RNA-seq untersucht [5]. Dadurch wurden zwei Wirtszell-Populationen entdeckt. Diese unterscheiden sich hinsichtlich ihrer Typ-I Interferon-Antwort (IFN), einem wichtigen Zweig der Immunantwort des Wirts, und stehen mit der von PhoP (einem bedeutenden Transkriptionsfaktor) gesteuerten Expression von SalmonellenVirulenzfaktoren in Verbindung. B, 20 Stunden nach der Infektion von Makrophagen mit Salmonellen werden zwei Populationen, die entweder aus Zellen mit replizierenden oder nicht-replizierenden Bakterien bestehen, isoliert und einzeln sequenziert [6]. Die Daten legen zwei entgegengesetzte Polarisierungs-Zustände der Makrophagen (M1, M2) offen, die mit dem Wachstumsverhalten der Salmonellen einhergehen. Dabei zeichnen sich M1-Makrophagen durch eine stark inflammatorische Immunantwort aus, wohingegen M2-Makrophagen entzündungshemmende Gene induzieren.
\end{abstract}

\footnotetext{
Abbildung 4 - Identifikation divergenter Transkriptom-Signaturen in Makrophagen mit replizierenden und nicht-replizierenden Bakterien mittels Single-cell RNA-seq (verändert nach [6]). Links: Die bioinformatische Analyse einzelner, nicht-infizierter (naiver) Makrophagen (grüne Punkte), stimulierter uninfizierter Nachbarzellen (blaue Punkte) sowie Makrophagen, die nicht-replizierende (orangefarbene Punkte) oder replizierende Bakterien enthalten (rote Punkte), hat drei unterschiedliche Gruppen (I-III) von Zellen aufgezeigt. Gruppe I umfasst naive Makrophagen, Gruppe II vorwiegend Makrophagen mit ruhenden Bakterien (dargestellt in der oberen Fluoreszenzabbildung, Maßstab $10 \mu \mathrm{m}$ ) und Gruppe III hauptsächlich Makrophagen, die mit replizierenden Bakterien infiziert
} 
sind (zu sehen in der unteren Fluoreszenzabbildung, Maßstab $10 \mu \mathrm{m}$ ). Rechts: Das Expressionsmuster von Makrophagen mit nicht-replizierenden Bakterien zeigt ein pro-inflammatorisches Profil (M1), wohingegen Zellen mit replizierenden Bakterien ein anti-inflammatorisches Profil (M2) aufweisen. Die unterschiedlichen Makrophagen-Populationen spiegeln sich in den in der Heat-Map dargestellten Expressionsmuster wider (blau: geringe Expression; orange: hohe Expression). 


\section{Korrespondenz}

Prof. Dr. Jörg Vogel

Institut für Molekulare Infektionsbiologie, Universität Würzburg, und Helmholtz-Institut für RNAbasierte Infektionsforschung (HIRI)

Josef-Schneider-Str. 2/D15

D-97080 Würzburg

\section{Autoren}

Dr. Antoine-Emmanuel Saliba studierte 2000-2005 Biotechnologie und Biochemie am INSA in Toulouse, Frankreich. Er promovierte 2005-2009 am Institut Curie (Paris, Frankreich). 2009-2013 arbeitete der als EMBL Interdisciplinary Postdoc (EIPOD)-Stipendiat am EMBL in Heidelberg, 2013-2016 als Post-Doktorand in der Arbeitsgruppe von Prof. J. Vogel an der Universität Würzburg. Seit 2017 ist er Gruppenleiter am Helmholtz-Institut für RNA-basierte Infektionsforschung (HIRI) in Würzburg.

Dr. Alexander J. Westermann studierte 2005-2010 Molecular Biosciences an der Universität Heidelberg (Deutschland). 2009 war er als Austauschwissenschaftler an der University of California (Berkeley, USA). Er promovierte 2010-2015 als Stipendiat des Bayerischen Elitenetzwerks in der Arbeitsgruppe von Prof. J. Vogel an der Universität Würzburg und ist dort seither als Post-Doktorand angestellt.

Prof. Dr. Jörg Vogel promovierte 1996-1999 an der Humboldt Universität (Berlin, Deutschland) und des Imperial College (London, UK). 2000-2001 war er Post-Doktorand in Uppsala (Schweden) und 20022003 als EMBO-Stipendiat an der Hebrew University in Jerusalem (Israel). 2004-2010 war er Gruppenleiter einer selbständigen Nachwuchsgruppe „RNA-Biologie“ am Max-Planck-Institut für Infektionsbiologie (Berlin, Deutschland). Seit 2009 ist er Direktor und W3-Professor des Instituts für Molekulare Infektionsbiologie der Universität Würzburg und zusätzlich seit 2017 Gründungsdirektor des Helmholtz-Instituts für RNA-basierte Infektionsforschung (HIRI) in Würzburg. 


\section{Bibliographie}

1. Bumann D (2015) Heterogeneous host-pathogen encounters: act locally, think globally. Cell Host Microbe 17:13-19

2. Monack DM, Mueller A, Falkow S (2004) Persistent bacterial infections: the interface of the pathogen and the host immune system. Nat Rev Microbiol 2:747-765

3. Burton NA, Schurmann N, Casse O, Steeb AK, Claudi B, Zankl J, Schmidt A, Bumann D (2014) Disparate impact of oxidative host defenses determines the fate of Salmonella during systemic infection in mice. Cell Host Microbe 15:72-83

4. Saliba AE, Westermann AJ, Gorski SA, Vogel J (2014) Single-cell RNA-sequencing: advances and future challenges. Nucleic Acids Res 42:8845-8860

5. Avraham R, Haseley N, Brown D, Penaranda C, Jijon HB, Trombetta JJ, Satija R, Shalek AK, Xavier RJ, Regev A, Hung DT (2015) Pathogen Cell-to-Cell Variability Drives Heterogeneity in Host Immune Responses. Cell 162:1309-1321

6. Saliba AE, Li L, Westermann AJ, Appenzeller S, Stapels DA, Schulte LN, Helaine S, Vogel J (2016) Single-cell RNA-seq ties macrophage polarization to growth rate of intracellular Salmonella. Nat Microbiol 2:16206

7. Westermann AJ, Forstner KU, Amman F, Barquist L, Chao Y, Schulte LN, Muller L, Reinhardt R, Stadler PF, Vogel J (2016) Dual RNA-seq unveils noncoding RNA functions in host-pathogen interactions. Nature 529:496-501 